\title{
Terminological Lexicon, A Staightforward Reflection of Globalized Develoments
}

\author{
Dr. Vilma Bello \\ University “Ismail Qemali” Vlorë, Albania \\ Email: vbello@yahoo.com
}

\section{Doi: $10.5901 / m j s s .2013 . v 4 n 4 p 147$}

\section{Abstract}

\begin{abstract}
Each period has its own historical, economical, political, social, cultural face. Each one of them has also its own linguistic face, which without any doubt goes alongside with the line of change of the science and technique. The Albanian language today is facing the strong cultural influence of the great languages (the big nations). In an open society, politically and economically, like the Albanian society today, it is felt the great pressure of the nations that are politically and economically powerful, which we are in contact with. The pressure is inevitable in this phase in which we are opening against the world. The globalization that has embraced even our language is a problem not only for the Albanian language. The terminological lexicon of the Albanian language has its own character. But the problems of terminology today require the attention of the society, with institutional support, so they can be treated in the right way and brought to solution. In a time when the dynamic changes in the field of terminology are so big, these developments can't be put out of the focus and care of an organization that links the scientific competence with the imperative one. Even the specialized organisms like the linguistic institutions, schools, media, are factors that push forward this important process.
\end{abstract}

Key words: terminology, lexicon, globalism, Albanian language, linguistic identity, English terms, linguistic policy.

\section{Introduction}

Under the influence of these global processes, all-inclusive and inevitable worldwide, the nowadays linguistic world has changed and keeps changing in dynamic and rapid way. Nowadays, like in all societies, even the Albanian one, even its communication language, has passed into a phase of impetuous development. The language, reflection of the social and material life, and also reflection of the history of a nation that speaks, changes during this dynamic. The nowadays linguistic reality springs up different problems dictated by these processes. In this dynamism of change, what we have to do with the terminological lexicon is the most important thing. In connection with the importance it has in the language and especially in its lexicon, terminology is are markable aspect more than any other part of lexicon as a straightforward expression of developments which is conditioned by the developments of scientific and technological concepts.

\subsection{Terminology goes alongside all these changes.}

Today, under the influence of the performance of the new concepts extraordinary big in size and quantity, closely related to the developments of the new fields in science and modern technology, with the use of sophisticated gadgets that have invaded all the world, like computers, mobile phones, the terminology as a special lexicon reflects straight for wardly these developments with its denominator units, by increasing, the same way as concepts do, in quantity and measure as big as these. Its problematic has become complex and needs to be re-estimated and seen under a new point of view, in accordance with all these developments dictated by factor out of the language.

The terminological problems need the attention of all the society, with individual and institutional support, so they can be treated in the right way and brought to solution.

In support of the thoughts, reactions and different estimations in relation to the changes that can be noticed in the Albanian language today, the Albanian language is facing a strong influence against the culture and big language (of the big nations). An open society, politically and economically like the Albanian society today, it is felt the pressure of those countries powerful politically and economically which we are in contact with. This pressure is inevitable in the first opening phases against the world. The world has entered now in the period of globalization. Globalization that has embraced even the language is not a problem only for the Albanian language or the languages of the other small nations, but it is a 
problem even for the gig nations. There is a big approach toward the English language in every field of life in Europe. Even the French language has felt the pressure of this language, even though in the past it has been the language of culture, politics and economy.

\subsection{Foreign ecperiences}

The same thing has happened with the German, Italian and Spanish languages.

As commonly accepted, foreign words have entered in the Albanian language in the overall lexicon in the terms of straightforward contacts for hundreds of years with the Albanian language (like latin and greek terms) while in the terminological lexicon, in the terms of contracts generally not straightforward and even becoming less straightforward with the foreign languages, laying different layers, like Italian terms, English terms(English is becoming like emphasized above, more and more sensitive about the global language of all the processes related to it) and even less Russian and German terms. It is impossible that the Albanian language with all its means fullfills the needs that it has in confront with the foreign countries.

Nowadays, in the occasion of globalism, the terminology and its use is shown as an important problem. The entrance of the foreign words in the overall lexicon is more limited, their acceptance even less allowed than in the terminological lexicon which carries the heavy weight of borrowing words from other languages, converting the terminology in the principal gate of entrance for the foreign lexicon.

\section{Literature Review and Hypotheses}

In terminology it is necessary and even more indispensable the work to re-estimate time and again its old elements, which can result unsuitable because of not finding room in the system with the new elements or because of the overloading with many concepts that are born, developed and changed every moment.

Nowadays, the problems of terminology have been observed both theoretically and practically. According to an overall thought of all the linguists, all this situation is conditioned by the new developments in science and by the impossibility of the Albanian language to answer immediately with its terminology." As a result it is obliged to borrow words from other languages." In the history of the development of the Albanian language we can distinguish two orientations of the work with lexicon, which move in a parallel way with each other, or one has preceded the other.

The first orientation has to do with the Renaissance purity (the priority of Albanian words against every foreign word) which was justified that time. If we see that from this side of history of Albanian terminology, we can monitor the development that our representatives of Renaissance made to the Albanian terminology such as Kristoforidhi, Frasheri and later Xhuvani.

The job done by them and their predecessors up to now, even though they did this individually, have raised all the terminological building, formed today, on strong foundations with the Albanian physiognomy. From the representatives of Renaissance generated the beginning of terminological bases of the essential fields of knowledge; from Sami Frasheri: grammar, geography: nyje-articles, emer-noun, mbiemer-adjective, peremer-pronoun, folje-verb, rrip-belt, dege-branch, hunde-nose, menge-sleeve etc. Naim Frasheri: geometry: matematike-mathematics, brinje-square sides, kend-angle, katror-square, pjestim- division, mbledhje-addition, mbetje-difference etc. Xhuvani: grammar: pasthirme-exclamation, rrjedhore-ablative case, numeror-number, kallezues-predicate, kundrinor-object, etc.

\subsection{The variety of hypotheses and limited results.}

The priority of the first orientation was because of the creation of the terminology with Albanian bases, even though of a low level, to make easier the understanding of the scientific knowledge. This continued later with a second phase of creation and laid the foundations of the terminology and later the raise of terminology as a sustainable and homogenous system. Generally in its base layers it is achieved a kind of crystallizing with the formation system of concepts, as a result and inoculation in terminological micro-systems of sustainable linguistic units with Albanian bases. Not all the renderings into the Albanian language resisted time and they were substituted again by foreign terms.

In the second orientation, as a new attitude, under a new light, is that of the influence from the other languages. The after coming development of science and technology in a national level, even international, brought the increase in the fields of knowledge and their differentiation. 


\subsubsection{The significant indicators of this paper research study.}

The great flow of foreign terms was felt especially in the textbooks of university students, in scientific and technical documents and especially in the free speech (feedback, feeder, managing, manager, dimension, solution, insufficiency, equilibrium). Although the process of creation of Albanian terminology continued, Albanian language reinforced passing through borrowing words from other languages: even in many dictionaries of different kinds prevail Albanian terms. What can be seen in this long process is that there was a strong opposition between the creation of a big amount of Albanian terms, reflected in the dictionaries composed on strong scientific principles and criteria, and their limited use in school texts, technical documents and the practice of speech.

\section{Methodology and Research Goal}

If in the terminology of the low level prevails the lexicon with the Albanian base in that of the universities it has prevailed and keep prevailing foreign terms: tension-tension, frekuence-frequency, specie-species, korrozion-corrosion, abrazionabrasion, centrifugal-centrifugal, neutral-neutral, potencial- potential, orbite-orbit, ingranazhe-gears, sklerotizm-sclerosis, produktivitet-productivity etc. In the entity of the foreign terms we can say that these of the Italian or French source are placed in front of the rendering in the Albanian language like:perzjerje-mixing(fg.melange),ndajthithje-absorption (fr. adsorption), zjarrtar-fireman(it. fokist), fjaleformim-wordformation(fr.formation des mots), shumesi-plural(fr. Pluralite)etc. But we can't state the same thing even for terms from the English source.

Prof. J. Thomai clearly emphases that the Albanian language shouldn't be considered as a language that has been closed up to now. There's no doubt that the Albanian language today is a complex- reality of many layers, with many different spaces of use, with changeable social values and roles, with multiple links with the nearby languages and those in the world.

After the 90-s although they kept entering the Albanian language as terms of different fields of knowledge, their flow was remarkable, for some objective and subjective reasons, we are all witness of the tremendous speed with which come in use the new technologies of broad consumption, alongside with proper terms. The Albanian language, not being able to face the pressure of new terms, willingly or not will accept them as they come from other languages(English).

From these reasons we can pick a.) the introduction of branches and fields of social activity, of knowledge and science unknown before, which is spoken and written about even in the means of mass communication, informatics, genetics, technology and new branches in consolidated fields $b$.) English language has a lot of influence and pressure on many European languages, as a result of political, economical, military, cultural, scientific etc. influence of the USA especially in the 90 -s up t now.

\section{The choice of strategic definitions}

Today, we define and know two important sides:

1. A limited influence of English in the established terminology (e.g maths, physics). A special place in the reflective attitude takes even the linguistic terminology.

2. The influence of English in new sciences.

The entrance gate of the foreign terms in the standard Albanian language is extending more and more due to the flow of the English terms. Taking into consideration that the biggest part of the foreign elements that enter through this gate are more or less similar in form and make up common patterns considering the context even for the other languages(computer, monitor, display),so these elements serve as an entrance gate for the other languages.

Different actors in different national languages need a mean of communication and terminology is the thread that links these actors of different languages. As a common flow passing through them, especially English terms, like the international terms in the biggest part of them, convert these gates into communicative utensils with the common measure circulating (foreign terms in each field).

Even the terminology of the Albanian language, part of this common flow, common even for the other languages, especially for those that serve as standard patterns of codification. This should happen even with the terminology of the Albanian language used in the other Albanian speaking regions in Kosovo and Macedonia.

The contradiction between the results of the elaborative activity in terminology and its conservation,on the hand, it makes it indispensable the introduction of the computerized methods in terminology to store and save all the subjects as a database, elaborated in the system, to give out the proper products(dictionaries of terminology) and to build an allinclusive terminological bank. Taking into account the globalization process of science, knowledge and technology and the 
European integrating process, the need for undertaking-pressing real measures for standardization and regulation of scientific and professional terminology in the Albanian language in all the fields.

All this means that the problems that we face today with the terminology must be put forward and solved alongside with the common problem of the other languages of the world as well. So, it is given a new orientation on the estimation and re- estimation of the foreign terms in the Albanian language, their attitude against them, their place in relation to the terms rendered in Albanian that compete with them, conforming them to a new linguistic policy, more liberal than ever. Prof. XH. Lloshi says: To use the Albanian equivalent alongside the borrowed words, to present other solutions to extend the site in hope that each one would be the best, and not to get stuck to the fixed idea: an unnecessary borrowing.

\subsection{The new orientation of the linguistic policy}

About the foreign terminology is closely related to the fulfillment of the near goal of being accepted to be part of the EU. To achieve this we have to work hard with the purpose to raise the Albanian language to the level of a language which is approximately achieving the status of the EU. Without doubt that terminology is one of the main factors that will make the language rise up and it is related with the other languages. The terminological lexicon, with common units (international) of the context (techno-scientific concepts) and personal(national) of the expression will certainly make the Albanian language come near the other EU language. Of course, among these units of expression (terms), foreign terms, especially those international, as a common cultural-linguistic stock, it will be their incarnation of the idea of cultural globalization in the linguistic field.

With all the continual effort made up to now to fulfill all the above chores in the field of terminology, yet we think that there is still a lot to be done by all of us, experts, linguists the highest level state and scientific institutions in this field. In a time when the dynamic changes in the field of terminology are so big, we can't leave these developments out of focus and care of organizations that join scientific competence to the imperative one.

Even the specialized organisms, like the linguistic institutions, schools, media wich are the factors that will push forward this important process.

\section{Bibliography}

Sh. Rokaj: Issues of the Albanian language, Albatros, Tirane, 2007.

A Duro: The Albanian word as a substitute of the foreign words and terms in The Terms And Sentence In The Albanian Language ( in context and form), Fan Noli, Tirane,2009

A Duro: Problems with the process of elaboration of terminology and its use in the speech, in 20-th International Seminary on the Albanian language, literature and culture, Prishtine,2001.

XH.Lloshi:The Albanian language, an open and dynamic language, in the scientific conference" The standard Albanian language and the Albanian society today", Tirane, 2003.

Xh. Thomai: The word, the term and linguistic normative, in the scientific conference"The state and development of Albanian terminology"Tirane,2009.

R. Ismajli: The standard language and the history of identities. The essential work in Albanology. Tirane 2009.

A Duro, F. Vrapi:Peculiarity of the terms, with English origin in the Albanian language, in the scientific conference" The state and development of the Albanian terminology" Tirane, 2009.

H. Shehu: About the English terms in today's mass communication means, in the scientific conference" Standard Albanian language and society today"Tirane 2003. 